\title{
Gestão de florestas públicas: uma revisão de literatura com ênfase à concessão florestal
}

Em 2006, a Lei de Gestão de Florestas Públicas (Lei 11.284 / 2006) foi criada para regulamentar o uso e gestão de florestas públicas para produção sustentável com princípios como regular o uso eficiente e racional das florestas. Em 1998, o governo brasileiro criava o programa nacional de florestas com objetivo de dinamizar o manejo florestal sustentável, mas em 2000 outro decreto sobre o programa apresentava objetivos que indicavam que manejar floresta era mais que explorar produtos madeireiros e não madeireiros, mas a regulamentação da gestão de florestas públicas somente ocorreu através da lei federal $n^{\circ} 11.284$, de 02 de março de 2006, criada para regulamentar o uso e gestão de florestas públicas para produção sustentável. A gestão de florestas públicas, pode ser realizada de três formas, criação de florestas nacionais, estaduais e municipais e a concessão florestal, objeto principal deste artigo de revisão. $\mathrm{O}$ trabalho foi realizado através de pesquisa bibliográfica sobre a gestão de florestas públicas de produção, com ênfase às concessões florestais. A pesquisa bibliográfica foi realizada em artigos científicos, e afins, sites oficiais do governo e de legislação vigente brasileira que trata sobre gestão de florestas. Um dos pontos fortes da lei de gestão de florestas públicas é que a partir dela as florestas públicas não poderiam mais ser privatizadas e a única forma de uso por empresas privadas seria através de concessão florestal. Executar a gestão de florestas públicas de produção no Brasil, requer antecipadamente o controle do desmatamento e da exploração ilegal de madeira, da grilagem de terra, a execução da regularização fundiária, a destinação de áreas as comunidades, a melhoria da gestão de unidades de conservação. De modo geral, a concessão florestal tornou-se mais um instrumento de gestão, mas não significante o suficiente, para inibir a exploração ilegal madeireira, conseguir aumentar a produção madeireira legal e gerar os benefícios ambientais, econômicos e sociais. A lei de gestão de florestas públicas requer mudanças, mas quando se trata da exploração da Amazônia, devemos ponderam com rigor os termos "celeridade e a flexibilidade".

Palavras-chave: Amazônia; Áreas Protegidas; Terras Públicas; Recursos Florestais

\section{Public forest management: a literature review with an emphasis on the forest concession}

\begin{abstract}
In 2006, the Law on Public Forest Management (Law 11,284/2006) was created to regulate the use and management of public forests for sustainable production with principles such as regulating the efficient and rational use of forests. In 1998, the Brazilian government created the national forest program with the objective of stimulate sustainable forest management, and in 2000 another decree on the program had objectives that indicated that manage forest was more than exploring timber and non-timber products, but the regulation of public forest management only occurred through federal law .11,284, of March 2, 2006, created to regulate the use and management of public forests for sustainable production. Public forest management can be carried out in three ways, creation of national, state and municipal forests and the forest concession, the main object of this review article. The work was carried out through bibliographic research on the management of public production forests, with an emphasis on forestry concessions. The bibliographic research was carried out in scientific articles, and the like, official websites of the government and current Brazilian legislation that deals with forest management. One of the strong points of the public forest management law is that from it public forests could no longer be privatized and the only form of use by private companies would be through forest concessions. The management of public production forests in Brazil requires advance control of deforestation and illegal logging, land grabbing, land regularization, allocation of areas to communities, and improvement of the management of conservation units. In general, the forest concession has become another management tool, but not significant enough to inhibit illegal logging, to increase legal timber production and to generate environmental, economic and social benefits. The law of public forest management requires changes, but when it comes to exploitation in the Amazon, we must carefully consider the terms "accelerate and flexibility".
\end{abstract}

Keywords: Amazon; Protected Areas; Public Lands; Forest Resources.

Topic: Planejamento, Gestão e Políticas Públicas Ambientais

Reviewed anonymously in the process of blind peer
Received: 04/04/2021

Approved: 28/04/2021

Cíntia da Cunha Soares (iD

Universidade Federal do Pará, Brasi

http://lattes.cnpq.br/8269808451972375

http://orcid.org/0000-0002-1654-3347

cintiacsoares@gmail.com

Maria das Graças Ferraz Bezerra (iD)

Universidade Federal do Pará, Brasil

http://lattes.cnpq.br/4772393906405054

https://orcid.org/0000-0002-0597-3165

mgferrazb@gmail.com

\section{Referencing this:}

SOARES, C. C.; BEZERRA, M. G. F.. Gestão de florestas públicas: uma revisão de literatura com ênfase à concessão florestal. Revista lbero

DOI: 10.6008/CBPC2179-6858.2021.004.0049 Americana de Ciências Ambientais, v.12, n.4, p.627-641, 2021. DOI: http://doi.org/10.6008/CBPC2179-6858.2021.004.0049 


\section{INTRODUÇÃO}

A lei federal $n^{\circ} 11.284$, de 02 de março de 2006 foi criada para regulamentar o uso e gestão de florestas públicas para produção sustentável, com princípios como regular o uso eficiente e racional das florestas, respeito ao direito da população, agregação de valor aos produtos da floresta, conscientização da população sobre a importância da conservação da floresta, garantia de condições estáveis para execução do manejo florestal, dentre outros de similar importância.

A concessão florestal considerada o instrumento "inovador" da LGFP é definido como delegação onerosa, feita pelo poder concedente, do direito de praticar manejo florestal sustentável para exploração de produtos e serviços numa unidade de manejo, mediante licitação, à pessoa jurídica, em consórcio ou não, que atenda às exigências do respectivo edital de licitação e demonstre capacidade para seu desempenho, por sua conta e risco e por prazo determinado. Na prática, após vencer um processo licitatório de concorrência de técnica e preço o concessionário tem a obrigação de cumprir o contrato de concessão florestal, dentre as obrigações pagar pelo $\mathrm{m}^{3}$ de madeira explorada adotando técnicas de manejo florestal, que vise minimizar os impactos causados na floresta.

Diante da interpretação do art. $4^{\circ}$ da lei $n^{\circ} 11.284 / 2006$, consta-se que a lei não orienta somente a concessão florestal, mas age como base fortalecedora para um ordenamento territorial com a criação de unidades de conservação como Florestas Nacionais (FLONA), Estaduais (FLOTA) e Municipais, Reservas Extrativistas, Reservas de Desenvolvimento Sustentável, projetos de assentamentos e afins. E a concessão florestal, desde a criação da lei, já era apresentada como um instrumento de gestão tanto para florestas nativas, como para florestas plantadas, que poderiam ocorrer em Florestas Nacionais, Estaduais e Municipais ou em terras públicas não destinadas, comumente conhecidas como floresta do tipo B ou glebas públicas.

As formas de gestão podem ser executadas independentes ou serem praticamente indispensáveis à realização uma da outra, isto é, para uma gestão em florestas não destinadas, primeiramente devem ser realizados estudos para destinação da floresta, identificando sua aptidão, podendo ser destinada a torna-se uma unidade de conservação, e caso, seja identificado moradia ou uso por comunidades locais, o poder público deve destinar essa área na forma de assentamentos ou unidades de conservação para uso exclusivo de comunidades e por fim, excluindo essas áreas, uma área é pré-definida para identificação do potencial florestal para produção madeireira e não madeireira, com o fim de estabelecer as áreas para concessão florestal.

Para definição de áreas para concessão florestal em unidades de conservação na categoria FLONA e afins é imprescindível a elaboração do Plano de Manejo, que é o documento técnico com fundamento nos objetivos da unidade de conservação, que estabelece o seu zoneamento e as normas que devem presidir o uso da área e o manejo dos recursos naturais, inclusive a implantação das estruturas físicas necessárias à gestão da unidade; isto é, na prática o zoneamento define os diferentes tipos de usos, para a concessão florestal, o plano de manejo deve conter uma zona com média intervenção, com uma zona específica denominada zona de manejo florestal (BRASIL, 2018). 
Considerando a experiência do estado do Pará, os órgãos gestores podem conceder florestas em terras públicas não destinadas, as denominadas florestas do tipo B ou glebas. E o estado do Pará iniciou a implantação de concessão florestal no Conjunto de Glebas Mamuru-Arapiuns formado por cinco grandes glebas a saber: Gleba Curumucuri, Glebas Nova Olinda, Nova Olinda II, Nova Olinda III e Gleba Mamuru, localizadas no Oeste do Pará.

A exemplo da experiência do Estado do Pará ocorrida em 2011, o Serviço Florestal Brasileiro a partir de 2021 passará a conceder florestas públicas não destinadas (tipo B ou Glebas) e considerando essa nova iniciativa, o MAPA e o Ministério da Economia publicaram a portaria interministerial $n^{\circ} 7$, de 30 de dezembro de 2020 que dispõe sobre a entrega ao MAPA de áreas de domínio da União identificadas no Plano Anual de Outorga Florestal (PAOF) para concessão florestal conforme § 10:

$\S 1$ 을 entrega a que se refere o caput será feita pela Superintendência do Patrimônio da União nos Estados - SPU/UF's ao Ministério da Agricultura, Pecuária e Abastecimento, por intermédio do Serviço Florestal Brasileiro, com os seguintes encargos, sem prejuízo do estabelecimento de outros:

I - promover a outorga do direito da prática do manejo florestal sustentável em florestas públicas federais, por meio da formalização de contratos de concessão florestal previstos no art. 4으, inciso III, da Lei no 11.284, de 2006; e

II - proporcionar os meios e as condições para que os objetivos das florestas públicas federais sob regime de concessão florestal, observadas as limitações e finalidades, possam ser alcançados de forma harmônica e eficaz. (BRASIL, 2020)

Ao conceder florestas em glebas, além de torna-las economicamente rentáveis, consideravelmente há uma inibição de possíveis invasões daquela que até então era considerada "terra sem lei". Para AzevedoRamos et al. (2018) esse tipo de ação em áreas não destinadas na Amazônia brasileira representa uma enorme oportunidade para melhorar a proteção do ecossistema amazônico. A destinação imediata dessas florestas públicas tem o potencial para ser maneira mais rápida e econômica de conter o desmatamento na região.

A descentralização de competências para cada esfera permite aos órgãos gestores terem autonomia para administrar suas florestas, elaborando e executando todos os procedimentos necessários para a consolidação da concessão florestal em seus territórios. Apesar da autonomia na gestão é importante frisar que os entes federativos trabalham em cooperação, geralmente, com o objetivo de apoiar e fortalecer os entes estaduais e municipais nas suas ações iniciais.

A criação do Serviço Florestal Brasileiro representou uma iniciativa pioneira para fortalecer o manejo florestal como uma alternativa imprescindível para o uso múltiplo e sustentável das florestas brasileiras, e como estratégia para se contrapor aos outros usos da terra que provocam invariavelmente à supressão das florestas nativas para implantação de atividades com maior retorno econômico, notadamente o desmatamento expansão da fronteira agropecuária, num processo de dilapidação do patrimônio florestal (BRASIL, 2011).

A cooperação técnica e administrativa, das competências constitucionais de proteção do meio ambiente e dos recursos naturais renováveis, visa promover, assim, a interação política e institucional da gestão descentralizada compartilhada. O pacto federativo tem por finalidade a descentralização das ações 
da esfera federal para os Estados. Tais pactos guardam peculiaridades entre si, pois levam em conta o status institucional e instrumental existente em cada unidade da federação. Essas peculiaridades é que permitem que se avance na definição de competências constitucionais, o que não significa que o órgão federal não continua sendo responsável pela gestão dos recursos naturais renováveis, objeto de repasse de atribuições.

A descentralização ambiental no Brasil ocorre com a criação do SISNAMA, uma estrutura de gestão que compreende União, estados e municípios. As unidades de conservação, os projetos de assentamentos e a gestão de florestas sob concessão florestal é realizada por todos os entes federativos, cada um no território sob sua jurisdição. Por exemplo, as unidades de conservação federais são de gestão do ICMBio, O SFB é o órgão gestor de concessão florestal e no estado do Pará e Amapá, respectivamente, o Ideflor-Bio e a SEMAAP, acumulam ambas as funções.

Conforme a legislação vigente, a concessão florestal permite a exploração de produtos e serviços florestais, que podem ocorrer após aprovação do Plano de Manejo Florestal Sustentável (PMFS), com a aprovação do Plano Operação Anual (POA), que gerara anualmente uma Autorização de Exploração Florestal (AUTEX/AUTEF), documento imprescindível para a exploração florestal através de manejo florestal sustentável, assim definido:

VI - manejo florestal sustentável: administração da floresta para a obtenção de benefícios econômicos, sociais e ambientais, respeitando-se os mecanismos de sustentação do ecossistema objeto do manejo e considerando-se, cumulativa ou alternativamente, a utilização de múltiplas espécies madeireiras, de múltiplos produtos e subprodutos não madeireiros, bem como a utilização de outros bens e serviços de natureza florestal;

Ao adotar o manejo florestal sustentável como o meio para explorar a floresta, penso que os autores da lei objetivavam o seu uso múltiplo, todavia os concessionários, que culturalmente exploram madeira em tora, apresentam certa dificuldade em valorizar outros produtos e/ou subprodutos e serviços, mesmo que a concessão traga essa possibilidade. Santana et al. (2012) conclui que a política de concessão florestal subestima o valor socioeconômico e ambiental da floresta, uma vez que apenas a madeira em tora está em pauta, não havendo efetividade no aproveitamento dos resíduos de madeira, e não computa o valor dos produtos não madeireiros e os serviços ambientais da floresta, assim como limita sua eficácia ao dificultar a participação de micro e pequenas empresas locais e das comunidades tradicionais.

A exploração madeireira, se conduzida seguindo práticas de manejo florestal sustentável, pode contribuir para a economia local e manutenção das florestas. E a concessão florestal, se bem implementada e monitorada, pode garantir essa melhoria na economia local, uma melhoria na qualidade de vida das comunidades locais e ainda garantir madeira de origem legal ao mercado da madeira. Sob uma perspectiva positiva, a concessão florestal é considerada indutora de importantes avanços, citando a inclusão de aspectos ambientais, sociais, culturais e econômicos aos princípios legais e também a intensificação da participação social e a promoção de um novo conceito de floresta pública (BONFIM et al., 2016).

Considerando o exposto, este artigo tem como objetivo realizar um levantamento teórico sobre a gestão de florestas públicas no Brasil, com ênfase à concessão florestal, visando avaliar as mudanças legais e estruturais ocorridos neste período. 


\section{METODOLOGIA}

O presente artigo foi realizado através de pesquisa bibliográfica sobre a gestão de florestas públicas de produção, com ênfase às concessões florestais. A pesquisa bibliográfica foi realizada em artigos científicos, e afins, sites oficiais do governo e de legislação vigente brasileira que trata sobre gestão de florestas.

\section{DISCUSSÃO TEÓRICA}

Em 1998, o governo brasileiro, através do decreto $n^{\circ} 2.473 / 1998$ criava o programa florestas nacionais com objetivo único de dinamizar o manejo florestal sustentável de produtos madeireiros e não madeireiros, em caráter empresarial ou comunitário. Este decreto foi revogado pelo decreto $n^{\circ} 3.420$, de 20 de abril de 2000 que também dispunha sobre criação do programa nacional de florestas a ser constituído de projetos concebidos e executados de forma participativa e integrada pelos governos federal, estaduais, distrital e municipais e a sociedade civil organizada, com os seguintes objetivos:

I - estimular o uso sustentável de florestas nativas e plantadas;

II - fomentar as atividades de reflorestamento, notadamente em pequenas propriedades rurais;

III - recuperar florestas de preservação permanente, de reserva legal e áreas alteradas;

IV - apoiar as iniciativas econômicas e sociais das populações que vivem em florestas;

$\mathrm{V}$ - reprimir desmatamentos ilegais e a extração predatória de produtos e subprodutos florestais, conter queimadas acidentais e prevenir incêndios florestais;

$\mathrm{VI}$ - promover o uso sustentável das florestas de produção, sejam nacionais, estaduais, distrital ou municipais;

VII - apoiar o desenvolvimento das indústrias de base florestal;

VIII - ampliar os mercados interno e externo de produtos e subprodutos florestais;

IX - valorizar os aspectos ambientais, sociais e econômicos dos serviços e dos benefícios proporcionados pelas florestas públicas e privadas;

X - estimular a proteção da biodiversidade e dos ecossistemas florestais. (BRASIL, 2000)

Alguns objetivos do programa nacional de florestas do decreto $n^{\circ} 3.420 / 2000$ serviriam como base para o conceito de Florestas nacionais, estaduais e municipais trazido pela lei $n^{\circ} 9.985 / 2000$, como uma área com cobertura florestal de espécies predominantemente nativas e tem como objetivo básico o uso múltiplo sustentável dos recursos florestais e a pesquisa científica, com ênfase em métodos para exploração sustentável de florestas nativas, bem como podemos identificar uma relação entre esses objetivos e os princípios da lei de gestão de florestas públicas, que passa a partir de 2006 a regulamentar sobre o uso de florestas públicas definidas como florestas, naturais ou plantadas, localizadas nos diversos biomas brasileiros, em bens sob o domínio da União, dos Estados, dos Municípios, do Distrito Federal ou das entidades da administração indireta.

O acesso de particulares às florestas era permitido, mas não havia um controle e monitoramento deste acesso, portanto o governo passou a dar um tratamento diferenciado às suas florestas, no sentido de exercer sobre as mesmas um controle e determinar um fim ou minimizar a exploração ilegal. A gestão de florestas públicas para produção sustentável tornou-se um marco legal para mudanças estruturais na gestão 
florestal no Brasil contribuindo para economia florestal, e gerando arrecadação a União, Estados e municípios e bem como benefícios sociais as comunidades locais (LOPES, 2017).

Segundo Azevedo-Ramos et al. (2015), o período que antecedeu a formulação do programa nacional de florestas foi caracterizado por discussões entre o governo, a indústria florestal e organizações da sociedade civil para testar a viabilidade e aceitação das estratégias que estavam sendo planejadas para a região amazônica. Uma estratégia chave para o uso sustentável em terras públicas era a possibilidade de conceder florestas para a exploração de madeira pelo setor privado.

Ainda sobre as florestas, um dos grandes diferenciais entre o programa nacional de florestas e a lei de gestão de florestas públicas de produção é que o programa trata também sobre florestas privadas e a lei n 11.284/2006 vem a regulamentar somente em florestas públicas e que a partir dela as florestas públicas não poderiam mais ser privatizadas e a única forma de uso destas florestas por empresas privadas seria através de concessão florestal.

A concessão florestal aparece como alternativa de política pública para monitoramento das atividades florestais, com vistas a seu desenvolvimento sustentável, pois algumas externalidades ficam evidentes quando a regulação não é feita de forma eficiente, podemos destacar os desmatamentos desordenados, levando ao possível esgotamento dos recursos renováveis (REMOR et al., 2009).

O objeto principal da concessão florestal é a exploração de produtos e serviços florestais e o concessionário tem direito ao uso apenas dos recursos previstos no contrato de concessão florestal. Por exemplo, se ele não expressar interesse em explorar produtos não madeireiros durante o processo licitatório, ele não poderá explorar esses produtos. É proibida a comercialização de créditos decorrentes da emissão evitada de carbono em florestas naturais. Mas caso tenhamos uma concessão florestal de reflorestamento de áreas degradadas, é dado o direito ao concessionário de comercializar crédito de carbono. Ainda não há concessão florestal de reflorestamento, mas é necessário iniciar uma discussão para esse tema, visto, o aumento de floresta desmatada, principalmente em terras públicas.

Rocha et al. (2006) questionava sobre a valoração do recurso florestal, para evitar a sua subvalorizarão, ou até mesmo a supervalorização, e que era importante entender que a valoração da floresta não poderia ficar somente baseada em conceitos econômicos e que uma avaliação mais ampla de benefícios sociais e ambientais deveriam ser consideradas. E passados mais de uma década, esses questionamentos continuam atuais, e há ainda hoje uma insegurança e muitas discussões em relação ao valor pago pelo recurso florestal explorado, ao uso múltiplo da floresta, aos impactos causados as comunidades locais.

Para Vieira (2010) a concessão florestal visa efetivar a presença humana e governamental nas florestas públicas brasileiras, capaz de combater a grilagem de terras e exploração ilegal de madeira, através de uma "ocupação" às terras públicas, instalando unidades de manejo florestal, sendo fundamental à utilização de mecanismos para o aproveitamento sustentável dos recursos florestais. E de fato, a presença de uma empresa concessionária na floresta pública pode inibir ou minimizar o acesso de terceiros, pois contratualmente a mesma assume corresponsabilidade de evitar ações ou omissões passíveis de gerar danos àquela floresta. 
A concessão florestal no Brasil vem sendo executada nas FLONAS, FLOTAS e florestas não destinadas nos estados do Pará, Rondônia, Amapá e Amazonas, no caso deste último, em 2020 o governo federal incluiu a concessão florestal em florestas do Amazonas no Programa de Parcerias de Investimentos (PPI), como uma agenda estratégica visando ampliar e fortalecer a interação entre o Estado e a iniciativa privada. Cabe aqui considerar que há pouco ou nenhum interesse dos bancos de investimento em apoiar os contratos de concessão florestal, por considerarem o manejo florestal uma atividade de alto risco. Portanto a inclusão da concessão florestal no programa de parcerias de investimentos (PPI) pode ser um atrativo significante de potenciais concessionários.

De acordo com o PAOF (SFB), há 18 contratos de concessão em execução que totalizam 1.601.837,11 milhão de hectares. As Unidades de Manejo Florestal concedidas estão localizadas nas Florestas Nacionais do Jamari e Jacundá, no estado de Rondônia, e nas Florestas Nacionais de Saracá-Taquera, Crepori, Altamira e Caxiuanã, no estado do Pará E conforme PAOF 2018 (Ideflor-Bio) do estado do Pará, há 09 contratos de concessão em execução que totalizam 483.435,49 mil hectares, com 03 unidades de manejo florestal no conjunto de glebas Mamuru-Arapiuns e 06 unidades na Floresta Estadual do Paru. E uma unidade de manejo florestal na FLOTA do Amapá com $67.434,78^{1}$ mil hectares. Portanto o Brasil possui 1,6 milhão e seiscentos mil de hectares sob concessão florestal (Tabela 1).

Tabela 1: Demonstrativo geral de áreas de florestas públicas concedidas no Brasil. ${ }^{2}$

\begin{tabular}{|c|c|c|c|}
\hline UC/GLEBA & ESTADO & CONCESSIONÁRIOS & $\begin{array}{l}\text { ÁREA } \\
\text { CONCEDIDA }\end{array}$ \\
\hline \multirow{3}{*}{ FLONA JAMARI } & RONDÔNIA & Madeflona Industrial Madeireira Ltda. & $17.176,36$ \\
\hline & RONDÔNIA & Amata S/A & $46.184,20$ \\
\hline & RONDÔNIA & Madeflona Industrial Madeireira Ltda. & $32.294,99$ \\
\hline \multirow[b]{2}{*}{ FLONA SARACA-TAQUERA } & PARÁ & Ebata Produtos Florestais Ltda. & $29.769,82$ \\
\hline & PARÁ & $\begin{array}{l}\text { Golf Indústria, Comércio e Exploração de } \\
\text { Madeireiras Ltda. }\end{array}$ & $18.933,62$ \\
\hline \multirow{2}{*}{ FLONA JACUNDÁ } & RONDÔNIA & Madeflona Industrial Madeireira Ltda. & $55.014,27$ \\
\hline & RONDÔNIA & Madeflona Industrial Madeireira Ltda. & $32.757,96$ \\
\hline \multirow{2}{*}{ FLONA SARACA-TAQUERA } & PARÁ & Ebata Produtos Florestais Ltda. & $26.898,00$ \\
\hline & PARÁ & Samise Indústria, Comércio e Exportação Ltda. & $59.408,00$ \\
\hline \multirow{2}{*}{ FLONA CREPORI } & PARÁ & Brasad'oc Timber Comércio de Madeiras Ltda. & $134.148,31$ \\
\hline & PARÁ & Brasad'oc Timber Comércio de Madeiras Ltda. & $59.863,90$ \\
\hline \multirow{4}{*}{ FLONA ALTAMIRA } & PARÁ & RRX Mineração e Serviços Ltda - EPP & $39.073,00$ \\
\hline & PARÁ & RRX Mineração e Serviços Ltda - EPP & $112.994,00$ \\
\hline & PARÁ & Patauá Florestal Ltda - SP & $98.414,00$ \\
\hline & PARÁ & Patauá Florestal Ltda - SP & $111.436,00$ \\
\hline \multirow{3}{*}{ FLONA CAXIUANA } & PARÁ & Benevides Madeiras Ltda. - EPP & $37.365,15$ \\
\hline & PARÁ & Benevides Madeiras Ltda. - EPP & $87.067,18$ \\
\hline & PARÁ & Cemal Comércio Ecológico de Madeiras Ltda. - EPP & $52.168,08$ \\
\hline TOTAL CONCESSÃO FEDERAL & & & $1.050 .966,84$ \\
\hline \multirow{6}{*}{ FLOTA PARU } & PARÁ & Madeireira Segredo Ltda EPP & $90.115,11$ \\
\hline & PARÁ & CEMAL - Com. Ecol de Madeiras & $99.868,54$ \\
\hline & PARÁ & RRX Mineração e Serviços Ltda & $24.341,41$ \\
\hline & PARÁ & RRX Mineração e Serviços Ltda & $42.249,52$ \\
\hline & PARÁ & RRX Mineração e Serviços Ltda & $24.965,52$ \\
\hline & PARÁ & Blue Timber Consultoria e Assessoria Ltda & $50.938,44$ \\
\hline \multirow{3}{*}{$\begin{array}{l}\text { CONJUNTO } \\
\text { ARAPIUNS }\end{array}$} & PARÁ & Amazônia Florestal Ltda & $85.417,91$ \\
\hline & PARÁ & LN Guerra Indústria e Comércio de Madeiras Ltda & $45.721,33$ \\
\hline & PARÁ & Rondobel Indústria e Comércio de Madeiras Ltda & $19.817,71$ \\
\hline
\end{tabular}

1 UMF originada de edital de licitação 2015, que ofertou 3 UMF's, sendo apenas assinado um contrato sob $n^{\circ} 001 / 2016$

2 Total de áreas concedidas até 2020. 
TOTAL CONCESSÃO ESTADO DO PARÁ

FLOTA DO AMAPÁ

TOTAL CONCESSÃO ESTADO DO AMAPÁ

Dados: SFB, Ideflor-Bio e SEMA-AP (2020).

Desse total de áreas concedidas, se considerarmos somente as áreas federais, 83\% estão no estado do Pará e $17 \%$ no estado de Rondônia. E se consideramos as áreas federais e estaduais, temos $84 \%$ de áreas sob concessão florestal no Pará, bastante significante em relação a Rondônia e Amapá. E quando avaliamos do total de áreas entre áreas federais e estaduais, temos $68 \%$ de área sob concessão em território federal e 32\% somando o estado do Amapá e Pará (Figura 1).

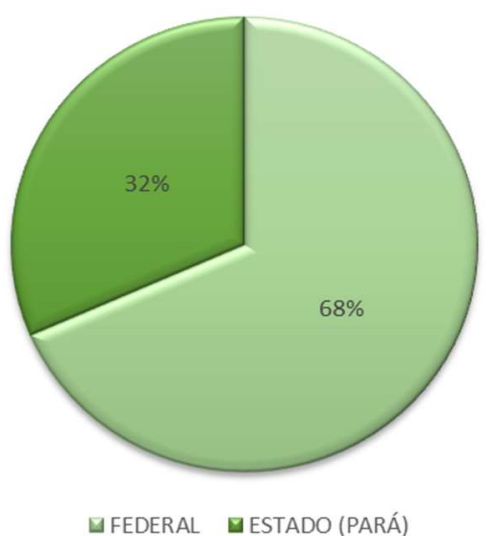

Figura 1: Florestas concedidas em florestas na União, no estado do Pará e Amapá (\%).

Castro et al. (2012) constatam que o estado do Pará já se encontra com boa parte de seu potencial florestal explorado, e que por isso, as novas políticas para o uso de florestas têm sido direcionadas, em grande parte, a esta região. Uma gestão eficiente de florestas públicas é capaz de proporcionar proteção, não somente contendo os avanços do desmatamento; é, também, capaz de promover igual distribuição nos direitos de uso dos recursos, bem como orientar usos sustentáveis entre empresários e comunidades tradicionais, no sentido de melhor conduzir os conflitos existentes pela terra e pelos recursos, explicando a concentração de $84 \%$ de florestas sob concessão florestal no Pará.

O Brasil é um país florestal com aproximadamente 4,8 milhões de quilômetros quadrados de florestas (56\% do seu território) - o que representa em torno de 12\% das florestas do mundo. As florestas do Brasil abrigam a maior diversidade biológica do planeta e contribuem de maneira notável na conservação das bacias hidrográficas do país. As florestas do Brasil contribuem ainda de maneira significativa na economia nacional. E, finalmente, essas florestas são vitais para milhões de brasileiros que as habitam, os quais dependem dos seus produtos e serviços ambientais (VERISSIMO et al., 2014).

Até 2006, a legislação era muito incipiente quando o assunto era sobre como explorar economicamente uma floresta pública. Mesmo aquelas que já estavam destinadas ao uso sustentável (Florestas Nacionais), também tinham carência de uma legislação. A Lei de Gestão de Florestas Públicas (Lei no. 11.284/06) foi elaborada, sendo uma conquista da sociedade brasileira. Resultado de uma grande mobilização social que envolveu 14 audiências púbicas e a participação de mais de 1200 instituições, dentre elas: governo federal, estados, organizações não governamentais (ONGs), setor empresarial, movimentos 
sociais, associações de trabalhadores, universidades e centros de pesquisa (SILVA et al., 2012). Desde o Código Florestal de 1965, esta é a primeira Lei editada no Brasil com o propósito de ordenar o uso sustentável dos recursos florestais, com vistas à produção e não apenas com finalidade de controle e fiscalização (BRASIL, 2011).

Oliveira et al. (2020) considera que a LGFP objetiva regular a gestão destas áreas, estabelecer atividades de produção sustentável, proteger o ecossistema, entre outras medidas ambientais e econômicas sustentáveis. E aponta que a gestão florestal para o país, compartilhada nos três níveis de governo a responsabilidade de gerir as florestas públicas para a produção sustentável, se fez necessária diante da extensão territorial do País que dificulta a gestão de políticas públicas de forma eficaz.

Segundo Castro et al. (2012), os problemas enfrentados pelo modelo de gestão florestal baseado em concessões, bem como os problemas existentes no interior de próprio modelo mostram que, ao mesmo tempo em que a concessão busca organizar a atividade madeireira de forma a amenizar os conflitos, ela pode ser tida como desencadeadora de outros conflitos ou potencializadora dos já existentes. Podem desencadear conflitos, inclusive, no interior de unidades de conservação, num possível ordenamento territorial ineficiente, assim como levantar questões fundiárias entre quilombolas e indígenas, sobrepostos a unidades de conservação, ou quando se trata de floresta não destinada, há a obrigatoriedade de destinar as florestas públicas para uso exclusivo comunitário.

De acordo com Azevedo-Ramos et al. (2015), a concessão florestal no Brasil está amadurecendo, de forma lenta, mas em constante evolução, contudo fazem críticas construtivas como em relação as condições administrativas do SFB que deveria ser um órgão exclusivo apenas para gerir as concessões florestais, visto que na LGFP também já havia outras 8 competências especificas, como manter a base de dados do Sistema Nacional de Informações Florestais (SNIF) e gerir o Fundo Nacional de Desenvolvimento Florestal (FNDF). Todavia, em 2019, o Ministério da Agricultura, Pecuária e Abastecimento, assumiu as concessões de florestas públicas, tornando-se em âmbito nacional, o poder concedente e responsável pela CGFlop ${ }^{3}$, o qual era competência do Ministério do Meio Ambiente. E o SFB que tinha 8 competências quando subordinado ao MMA, passa a ter 26 competências subordinado ao MAPA, incluindo a gestão do CAR (BRASIL, 2019).

Há muitas críticas ao governo federal, para esta mudança da subordinação do SFB ao MAPA, pois numa visão geral, a execução da gestão de florestas públicas tornou-se mais complexa e burocrática, visto que antes, as decisões eram tomadas por um único ministério e agora, envolvem 2 ministérios, o MMA e o MAPA, que, respectivamente, para um compete a política de preservação, conservação e uso dos recursos sustentáveis, incluindo a gestão de unidades de conservação, neste caso, as FLONAS e outro a política agrícola, que passou a incluir a gestão de florestas públicas de produção. Outra crítica que faço a essa mudança é que as competências do MAPA estão relacionadas a política agrícola ${ }^{4}$, abrangidas a agricultura, a pecuária, a agroindústria, a agroenergia, as florestas plantadas (BRASIL, 2019), dentre outras, temas sempre discutidos em divergência ao manejo florestal de floresta nativa, por exemplo, que atualmente é o principal 
objeto da concessão florestal.

A concessão florestal, ao longo do tempo, tem focado na exploração de madeira em tora, com pouca relevância para a exploração de resíduos florestais e produtos não madeireiros e em relação aos serviços florestais, acredito que devido o interesse pelas áreas de concessão serem por empresas madeireiras, não há expertise para a execução de serviços florestais, mesmo que o conceito de manejo florestal sustentável definido na LGFP seja abrangente a utilização de múltiplas espécies madeireiras, de múltiplos produtos e subprodutos não madeireiros, bem como a utilização de outros bens e serviços de natureza (BRASIL, 2006). Podemos evidenciar esse foco na madeira em tora, quando avaliamos os editais de licitação lançados pelo SFB e por órgãos estaduais, o qual nos mais recentes, serviços florestais não consta mais como indicador de desempenho para proposta técnica no processo licitatório (Quadro 2).

Os indicadores técnicos são apresentados em cada edital de concessão florestal e eles são o grande diferencial técnico em relação aos PMFS de áreas privadas. Eles fazem parte da etapa de "julgamento de propostas técnicas", em que cada licitante deve apresentar como proposta, dentro dos parâmetros estabelecidos em edital. Esses indicadores devem atender a critérios que são: a. o menor impacto ambiental; b. os maiores benefícios sociais diretos; c. a maior eficiência e d. a maior agregação de valor ao produto ou serviço florestal na região da concessão (BRASIL, 2006).

Conforme podemos observar no quadro 01, houve muitas alterações destes indicadores, alguns que foram eliminados, outros que se tornaram bonificadores e vice-versa, bem como aqueles que foram sendo criados. Podemos observar que indicador social "Investimento em infraestrutura e serviços para comunidade local" e o indicador de agregação de valor "Grau de processamento local do produto", se mantiveram em todos os editais publicados, devido à importância social e impacto direto causado pela exploração madeireira as comunidades locais. E a obrigatoriedade do concessionário em agregar valor ao produto explorado da floresta.

Ao avaliarmos o relatório de gestão 2019 elaborado pelo SFB e os relatórios de auditorias florestais independentes (AFI) de contratos sob a gestão do Ideflor-Bio, elaborados por organismos de auditoria florestal, conclui-se que alguns indicadores técnicos podem não estar sendo cumpridos integralmente ou há uma dificuldade por parte dos órgãos gestores em avaliarem seu cumprimento. Baseado na experiência no Pará, confirmo que os concessionários apresentam dificuldades para cumprir os critérios técnicos. Costumo dizer que, culturalmente, as empresas madeireiras, que hoje, são concessionárias, tem a floresta apenas como uma fonte de produção de madeira que dará retorno financeiro, e essa cultura precisa ser modificada e devem tornar os indicadores técnicos, parte do PMFS, pois enquanto tratarem de formas distintas, os indicadores técnicos não terão a significância prevista na lei.

Os editais de concessão florestal também apresentam os indicadores técnicos denominados bonificadores que não são indicadores obrigatórios, mas caso sejam executados no decorrer do contrato, podem gerar ao concessionário, desconto no valor pago pelo recurso florestal explorado, não ultrapassando o preço mínimo para cada UMF apresentado em edital. Podemos observar no quadro 1 que houve uma redução dos números de indicadores técnicos obrigatórios, com alguns indicadores que sofreram 
reformulação e tornaram-se indicadores bonificadores, que visavam, principalmente, tornar os editais de concessão florestal mais atrativos.

Quadro 1: Quadro geral de indicadores técnicos constantes nos editais de concessão florestal no Brasil.

\begin{tabular}{|c|c|c|c|c|c|c|c|c|c|c|c|c|c|}
\hline \multirow[b]{2}{*}{$\mathbf{N}$} & \multirow[b]{2}{*}{ INDICADORES TÉCNICOS } & \multicolumn{12}{|c|}{ EDITAIS } \\
\hline & & $\begin{array}{l}001 / \\
2007\end{array}$ & $\begin{array}{l}001 / \\
2009\end{array}$ & $\begin{array}{l}001 / \\
2011 \\
(P A)^{5}\end{array}$ & $\begin{array}{l}002 / \\
2011 \\
(\mathrm{PA})\end{array}$ & $\begin{array}{l}001 / \\
2012\end{array}$ & $\begin{array}{l}002 / \\
2012\end{array}$ & $\begin{array}{l}001 / \\
2013\end{array}$ & $\begin{array}{l}003 / \\
2013\end{array}$ & $\begin{array}{l}001 / \\
2013 \\
(\mathrm{PA})\end{array}$ & $\begin{array}{l}001 / \\
2015\end{array}$ & $\begin{array}{l}001 / \\
2015 \\
(A P)^{6}\end{array}$ & $\begin{array}{l}001 / \\
2018 \\
(\mathrm{PA})\end{array}$ \\
\hline 1 & $\begin{array}{l}\text { Monitoramento da } \\
\text { dinâmica de crescimento } \\
\text { e da recuperação da } \\
\text { floresta I(parcelas } \\
\text { permanentes) }\end{array}$ & $x$ & $x$ & & & & & & & & & & \\
\hline 2 & $\begin{array}{l}\text { Redução de danos a } \\
\text { floresta durante } \\
\text { exploração florestal }\end{array}$ & $x$ & $x$ & $x$ & $x$ & $x$ & $x$ & & & $x$ & & & $x$ \\
\hline 3 & $\begin{array}{l}\text { Investimento em } \\
\text { infraestrutura e serviços } \\
\text { para comunidade local }\end{array}$ & $X$ & $X$ & $x$ & $x$ & $x$ & $x$ & $x$ & $x$ & $X$ & $X$ & $x$ & $x$ \\
\hline 4 & $\begin{array}{l}\text { Geração de empregos } \\
\text { locais }\end{array}$ & $x$ & $x$ & $X$ & & & & & & & & & \\
\hline 5 & $\begin{array}{l}\text { Geração de empregos da } \\
\text { concessão florestal }\end{array}$ & $X$ & $X$ & $x$ & $x$ & $x$ & $x$ & & & $X$ & & & $X$ \\
\hline 6 & $\begin{array}{l}\text { Diversidade de produtos } \\
\text { explorados na UMF }\end{array}$ & $x$ & $x$ & $x$ & $x$ & & & & & & & & \\
\hline 7 & $\begin{array}{l}\text { Diversidade de espécies } \\
\text { exploradas na UMF }\end{array}$ & $x$ & $x$ & $x$ & $x$ & & & & & $x$ & & & $x$ \\
\hline 8 & $\begin{array}{l}\text { Diversidade de serviços } \\
\text { explorados }\end{array}$ & $x$ & $x$ & $x$ & & & & & & & & & \\
\hline 9 & $\begin{array}{l}\text { Grau de processamento } \\
\text { local do produto }\end{array}$ & $X$ & $X$ & $x$ & $x$ & $x$ & $x$ & $X$ & $X$ & $x$ & $x$ & $x$ & $X$ \\
\hline 10 & $\begin{array}{l}\text { Aproveitamento de } \\
\text { resíduos florestais }\end{array}$ & & & & & $x$ & $x$ & & & $x$ & & & \\
\hline 11 & $\begin{array}{l}\text { Implantação e } \\
\text { manutenção de sistema } \\
\text { de gestão e desempenho } \\
\text { de qualidade das } \\
\text { operações florestais }\end{array}$ & & & & & & & $x$ & $x$ & & $x$ & $x$ & \\
\hline 12 & $\begin{array}{ll}\text { Investimento } & \text { na } \\
\text { proteção da floresta } & \end{array}$ & & & & & & & & & & & $x$ & \\
\hline 13 & $\begin{array}{l}\text { Adoção de inovações } \\
\text { técnicas e tecnológicas } \\
\text { associadas ao manejo } \\
\text { florestal }\end{array}$ & & & & & & & $x$ & $x$ & & $x$ & $x$ & \\
\hline
\end{tabular}

Fonte: Editais de concessão florestal (SFB, Ideflor-Bio e SEMA-AP)

Para Muniz et al. (2019), a política de concessão de florestas públicas, surgiu como uma solução, diante de um quadro de escassez de recursos do setor público e falhas no monitoramento e fiscalização, com o princípio de impedir a degradação e devastação pela ocupação desordenada de atividades e, ao mesmo tempo, viabilizar a gestão sustentável das mesmas, aumentando a renda e melhorando a qualidade de vida das populações locais. Conforme apresentado no quadro $01 \mathrm{~b}$, os indicadores sociais como investimento nas comunidades locais, geração de emprego local, participação da comunidade local na exploração de produtos na unidade de manejo são pontos fortes para alcançar a melhoria de qualidade de vida dessas populações locais.

\footnotetext{
${ }^{5}$ Editais lançados pelo estado do Pará

${ }^{6}$ Edital lançado pelo estado do Amapá. 
Outro ponto que considero importante para avaliar na gestão de florestas públicas, está relacionado ao SFB e aos órgãos gestores estaduais e municipais, que não realizam a gestão isolados, é necessário o envolvimento de outros órgãos que compõem o SISNAMA, por exemplo, como o ICMBio ,IBAMA, Secretarias estaduais de meio ambiente (BRASIL, 1981), juntamente com órgãos fundiários como INCRA, SPU, ITERPA (no caso do estado do Pará), FUNAI, e com apoio das organizações sociais. Sem que haja de fato, uma política estruturante entre esses órgãos, a gestão de florestas públicas poderá não ser eficiente a longo prazo, onde as florestas públicas continuarão sendo ameaçadas pela grilagem, exploração ilegal de madeira e outras atividades potencialmente degradantes.

Para Chules et al. (2018), embora as concessões florestais dependam de outros órgãos, apenas o Serviço Florestal Brasileiro tem o manejo florestal sustentável com escopo principal. O ICMBio tem sua atuação voltada para atividades de preservação e conservação, num espectro amplo, sendo o manejo florestal sustentável apenas uma das estratégias de conservação das quais o órgão participa. Voltado para atividades fiscalizatórias e licenciadoras, o IBAMA também tem atuação mais ampla. O processo de concessão tem etapas que dependem de órgãos que não têm sua estrutura e esforços voltados para política de concessões florestais da mesma forma como Serviço Florestal Brasileiro.

Quando partimos da premissa econômica, Silva et al. (2015) questionam que a lei gestão cria uma possibilidade de exploração econômica da floresta, que vise, primeiramente, preservar florestas públicas sob o risco de exploração excessiva. Pontuam que no momento em que o Estado e os estados passam a permitir o uso dos recursos florestais, ao mesmo tempo passa a impor responsabilidades as empresas concessionárias. As empresas que se submetem ao processo licitatório e tornam-se concessionarias precisam entender que assinam um contrato para explorar recursos florestais de forma ordenada, com limites de exploração fundamentados na legislação vigente, e que devem considerar o uso eficiente da floresta com a sua manutenção em pé como sua responsabilidade.

Como forma de aumentar a adoção das técnicas de manejo florestal sustentável, foi instituída a política de concessão florestal, implementada pelo Governo Federal, por meio da Lei no 11.284/2006 (BRASIL, 2006). Além de garantir a oferta contínua de produtos florestais madeireiros e não madeireiros, a concessão florestal também objetiva desacelerar a ocupação desordenada e a exploração ilegal das florestas. Assim, é possível manejar florestas públicas, podendo retirar dela produtos madeireiros e não madeireiros, em que os concessionários pagam ao ente federativo valores definidos no processo de licitação pública das áreas a serem manejadas (RODRIGUES et al., 2020).

Com o avanço da ciência, manejos florestais devem ser adaptados, validados e ancorados na legislação florestal passo a passo por políticas públicas de forma a abordar racionalmente a sustentabilidade na gestão dos recursos de madeireiros (ANDRADE et al., 2019). A adoção do manejo sustentável é fundamental para a manutenção das florestas tropicais e as pesquisas precisam avançar no sentido de auxiliar a normatização, com base na ecologia das espécies e que contemple as particularidades ambientais da Amazônia - e não somente na produção volumétrica. Infelizmente, a informação existente sobre os limites toleráveis pelas espécies/ecossistemas, em contextos específicos para a Amazônia, é escassa (SILVA et al., 
2009).

Para Siviero et al. (2020), a existência de um enorme potencial das florestas primárias, sejam aquelas intensivamente exploradas no passado, sejam as florestas em reservas federais, estaduais ou privadas, clama pela concepção de políticas e legislação compatíveis com cada característica e tipologia florestal, de modo a valorizar esse recurso natural e fortalecer a indústria madeireira de base florestal. Com a adoção de um manejo florestal tecnicamente correto e baseado na vocação histórica da indústria madeireira, esse setor pode contribuir significativamente para o desenvolvimento sustentável da Amazônia.

Roma et al. (2013), apontam que as concessões florestais também teriam o poder de fornecer, sob uma perspectiva de longo prazo, uma matéria-prima de fácil monitoramento desde o seu corte e que estaria livre de problemas relacionados à questão fundiária. Esta junção de estabilidade na oferta, na rastreabilidade e na ausência de conflitos relacionados aos direitos de propriedade poderia facilitar, consideravelmente, o acesso a mercados internacionais, sobretudo na atual conjuntura, em que importantes parceiros comerciais do Brasil vêm aumentando o rigor com relação à origem e à legalidade da madeira adquirida. Todavia, mesmo com a concessão florestal produzindo madeira legal, os índices de exploração ilegal de madeira na Amazônia, ainda é relevante, e estamos tratando de uma concorrência desleal, pois essa madeira explorada ilegalmente se torna "legal", com a compra de créditos de madeira, o que permite o acesso dessa madeira ao mercado seja ele interno ou externo.

Note-se que a ideia do manejo permeia de forma tão absoluta a Lei de Gestão de Florestas Públicas que os próprios conceitos de produtos e serviços florestais os consideram como decorrentes do manejo florestal e o fomento ao manejo florestal é consagrado entre os princípios da gestão das florestas públicas. Há uma clara mensagem do legislador: não existe outra possibilidade de produção em floresta pública senão de forma sustentável e o instrumento válido para atingi-la é o manejo florestal (BLIACHERIS, 2011). Para a LGFP, a floresta pública precisa ser administrada, o uso do recurso somente será explorado pela via do manejo florestal, que gerará o produto legal para o mercado madeireiro.

E ainda sobre as mudanças sobre a gestão de florestas públicas de produção, tramita na câmara de deputados federais, o projeto de Lei $n^{\circ}$ 5.518/2020 que visa alterar a Lei n.. 11.284, de 2 de março de 2006, para conferir maior celeridade ao processo licitatório, flexibilidade aos contratos e atratividade ao modelo de negócio das concessões florestais.

O projeto de lei apresenta alterações que ainda merecem muitas discussões, como tornar o Plano Anual de Outorga Florestal, um plano plurianual, a inclusão de novas modalidades de concessão florestal, como concessão para conservação e concessão para restauração de florestas a possibilidade acesso ao patrimônio genético para fins de conservação, pesquisa, desenvolvimento e bioprospecção, desde que em conformidade com a Lei № 13.123/2015, exploração de recursos pesqueiros ou da fauna silvestre e serviços ambientais, que incluem comercialização de crédito de carbono. Há proposta de mudanças referentes ao licenciamento que também merecem uma discussão mais ampla. Mudanças no processo licitatório, no regime econômico-financeiro dos contratos, dentre outras que também constam no projeto de lei, que são justificadas, em especial pela importância estratégica das concessões florestais para o crescimento do setor 
florestal na Amazônia, dar celeridade ao processo desde o processo licitatório até os procedimentos de licenciamento, visando fortalecer o instrumento concessão.

\section{CONCLUSÕES}

De forma geral, atuar na gestão de florestas no Brasil, requer antecipadamente o controle do desmatamento e da exploração ilegal de madeira, da grilagem de terra, a execução da regularização fundiária, a destinação de áreas as comunidades, a melhoria da gestão de unidades de conservação ou não alcançaremos princípios estabelecidos na lei. E que um projeto de lei que vise apenas dar celeridade aos processos e que não considere minimamente esses pontos, pode não garantir o desenvolvimento econômico e a conservação ambiental na Amazônia. A lei de gestão de florestas públicas requer mudanças, mas quando se trata da exploração da Amazônia, devemos ponderam com rigor os termos "celeridade e a flexibilidade".

\section{REFERÊNCIAS}

ANDRADE, V. H. F.; MACHADO, S. A.; FIGUEIREDO FILHO, A.; BOTOSSO, P. C.; MIRANDA, B. P.; SCHÖNGART, J.. Growth models for two commercial tree species in upland forests of the Southern Brazilian Amazon. Forest Ecology and Management, v.438, p.215-223, 2019. DOI: https://doi.org/10.1016/i.foreco.2019.02.030

AZEVEDO-RAMOS, C.; SILVA, J. N. M.; MERRY, F.. The evolution of Brazilian forest concessions. Elementa: Science of the Anthropocene, v.3, n.48, p.1-8, 2015. DOI: http://doi.org/10.12952/journal.elementa.000048

AZEVEDO-RAMOS, C.; MOUTINHO, P.. No man's land in the Brazilian Amazon: Could undesignated public forests slow Amazon deforestation?. Land Use Policy, v.73 p.125-127, 2018. DOI: http://doi.org/10.1016/j.landusepol.2018.01.005

BLIACHERIS, M. W.. Manejo florestal sustentável: uma perspectiva jurídica. Revista da AGU, v.10, n.29, 2011. DOI: http://doi.org/10.10.25109/2525-328X.v.10.n.29.2011.152

BONFIM, S. L.; D’AVIGNON, A. L. A.; SOUZA, A. N.; FONTES, P. J. P.; JOAQUIM, M. S.. O potencial da concessão de florestas públicas para o desenvolvimento socioeconômico e geração de emprego na Amazônia Legal. Rev. Serv. Público, v.67 n.4, p.649-670, 2016.

BRASIL. Lei n. 6.938, de 31 de agosto de 1981. Dispõe sobre a Política Nacional do Meio Ambiente, seus fins e mecanismos de formulação e aplicação, e dá outras providências. Brasília: DOU, 1981.

BRASIL. Lei n. 9.985, de 18 de julho de 2000. Institui o Sistema Nacional de Unidades de Conservação da Natureza e dá outras providências. Brasília: DOU, 2000.

BRASIL. Lei n. 11.284, de 02 de março de 2006. Dispõe sobre a gestão de florestas públicas para a produção sustentável. Brasília: DOU, 2006.

BRASIL. Estudo Nacional do Setor Florestal Brasileiro. Brasilia: MMA, 2011

BRASIL. Roteiro metodológico para elaboração e revisão de planos de manejo das unidades de conservação federais. Brasília: ICMBio, 2018.

BRASIL. Lei n. 13.844, de 18 de junho de 2019. Estabelece a organização básica dos órgãos da Presidência da República e dos Ministérios. Brasília: DOU, 2019.

BRASIL. Relatório de gestão de florestas públicas 2019. Brasília: SFB, 2019

BRASIL. Plano anual de outorga florestal 2020. Brasília: SFB, 2020.

BRASIL. Projeto de Lei $\mathbf{n} . \mathbf{5 5 1 8}$, de 2020. Altera a Lei n.ㅇ 11.284, de 2 de março de 2006, para conferir maior celeridade ao processo licitatório, flexibilidade aos contratos e atratividade ao modelo de negócio das concessões florestais. Brasília: DOU, 2020.

CASTRO, E. M. R.; NASCIMENTO, S. M.; CORREA, S. A.. Política florestal e empresas do setor madeireiro: o que há de novo em suas estratégias ?. R. Pós Ci. Soc. v.9, 18, 2012.

CHULES, E. L.; SCARDUA, F. P.; MARTINS, R. C. C.. Desafios da implementação da política de concessões florestais federais no Brasil. Rev. Direito Econ. Socioambiental, v.9, n.1, p.295318, 2018. DOI:

http://doi.org/10.7213/rev.dir.econ.soc.v9i1.18351

LOPES, S. R.. Gestão das florestas públicas com ênfase a participação social. Lex Humana, v.9, n.2, p.133-155, 2017.

MUNIZ, T. F.; PINHEIRO, A. S. O.. Concessão florestal como instrumento para redução de exploração ilegal madeireira em Unidades de Conservação em Rondônia. Revista FAROL, v.8, n.8, p.121-142, 2019.

REMOR, A. R.; HILLBUCHT , R. O.. Concessões de florestas públicas: estratégia viável para o desenvolvimento sustentável do setor florestal na Amazônia. Estratégia e Negócios, v.2, n.1, 2009.

ROCHA, K.; MOREIRA, A. R. B.; REIS, E. J.; CARVALHO, L.. The market value of forest concessions in the Brazilian Amazon: 
a Real Option approach. Forest Policy and Economics, v. 8 p.149-160, 2006. DOI:

http://doi.org/10.1016/i.forpol.2004.05.008

ROMA, J. C.; ANDRADE, A. L. C.. Economia, concessões florestais e a exploração sustentável de madeira. Boletim Regional, Urbano e Ambiental, v.08, 2013.

RODRIGUES, M. I.; SOUZA, Á. N.; JOAQUIM, M. S.; LUSTOSA JÚNIOR, I. M.; PEREIRA, R. S.. Concessão florestal na Amazônia brasileira. Ci. Fl, v.30, n.4, p.1299-1308, 2020. DOI: https://doi.org/10.5902/1980509821658

SILVA, K. E.; RIBEIRO, C. A. A. S.; MARTINS, S. V.; SANTOS, S. V.. Concessões de florestas públicas na Amazônia: desafios para o uso sustentável dos recursos florestais. Bioikos, v.23, n.2, p.91-102, 2009.

SILVA, D. S. N.; BORGES, L. A. C.; SILVA, G.; DAS D. N.. Gestão sustentável das florestas públicas no Brasil (Lei 11.284/06) VIII Fórum Ambiental da Alta Paulista, v.8, n.5, p.152-167, 2012. DOI: http://doi.org/10.17271/19800827852012296
SILVA, L. X.; SPOHR, G.. Mudança institucional e direito de propriedade: interpretações econômicas da Lei Geral de Florestas Públicas brasileiras. Ensaios FEE, v.36, n.3, p.707728, 2015.

SIVIERO, M. A.; RUSCHEL, A. R.; YARED, J. A. G.; VIEIRA, S. B.; SALES, A.; PEREIRA, J. F.; AGUIAR, O. J. R.; BRIENZA JUNIOR, S.; PEREIRA, P. C. G.; BERBERIAN, G. A.; CONTINI, K. P. S. Manejo de florestas naturais degradadas na Amazônia: estudo de caso sobre critérios de colheita. Ci. FI., v.30, n.1, p.43-59, 2020.

DOI: https://doi.org/10.5902/1980509825856

VERISSIMO, A.; PEREIRA, D.. Produção na Amazônia Florestal: características, desafios e oportunidades. Parc. Estrat., v.19, n.38, p.13-44, 2014.

VIEIRA, V. R.. Anotações sobre a lei de gestão de florestas públicas e as licitações para concessão florestal. Revista Processus de Estudos de Gestão, jurídicos e Financeiros, v.1, n.4, p.118-123, 2010

A CBPC - Companhia Brasileira de Produção Científica (CNPJ: 11.221.422/0001-03) detém os direitos materiais desta publicação. Os direitos referem-se à publicação do trabalho em qualquer parte do mundo, incluindo os direitos às renovaç̃es, expansões e disseminações da contribuiç̃o, bem como outros direitos subsidiários. Todos os trabalhos publicados eletronicamente poderão posteriormente ser publicados em coletâneas impressas sob coordenação da Sustenere Publishing, da Companhia Brasileira de Produção Científica e seus parceiros autorizados. Os (as) autores (as) preservam os direitos autorais, mas não têm permissão para a publicação da contribuição em outro meio, impresso ou digital, em português ou em tradução. 